Padmanabhanunni, A. \& Edwards, D. (2013). Victimisation in the lives of lesbian-identified women in South Africa: implications for clinical assessment and treatment. Journal of Psychology in Africa, 23(3): 385-392

\title{
Victimisation in the Lives of Lesbian-Identified Women in South Africa: Implications for Clinical Assessment and Treatment
}

\author{
Anita Padmanabhanunni and David Edwards
}

\begin{abstract}
Few clinical studies have examined victimisation in the lives of lesbian women in South Africa and whether there are distinct implications for psychological treatment. This paper presents the assessment and treatment of a lesbian-identified South African survivor of childhood sexual abuse who, as an adult, was raped and later gang raped. Her victimisation in adulthood represented 'corrective rape' motivated by the prejudiced assumption that the sexuality of lesbian women is pathological and should be 'corrected' through rape. This paper lends insights into the role of heterosexism in shaping vulnerability to victimisation and the process of recovery. It provides recommendations for work with sexual minority clients and highlights the implications when there is an absence of safety and support in the external environment.
\end{abstract}

Clinical work in the area of sexual violence in South Africa has been directed at understanding the impact of sexual victimisation in the lives of heterosexual women and the process involved in recovery. Few clinical studies have specifically examined the implications of victimisation in the lives of lesbian-identified women, contributing to a significant gap in the literature. A growing body of research suggests that lesbian women are exposed to traumatic events at higher rates compared to their heterosexual counterparts (Alessi, Meyer, \& Martin, 2013). This increased risk is attributed to pervasive societal heterosexism, defined as the cultural ideology that normalises and privileges heterosexuality and "denies, denigrates and stigmatises any form of non-heterosexual identity, behaviour or relationship" (Herek 1990, as cited in Smith, Oades, \& McCarthy, 2012, p.5). It manifests as routine encounters with prejudice and discrimination (e.g., hostile looks, rude gestures, and differential treatment) as well as more overt hostility in the form of verbal, physical, or sexual abuse (Swim, Pearson, \& Johnston, 2007).

In South Africa, such overt acts of hostility take the form of 'corrective rape', a term coined by the popular media to refer to rape motivated by the prejudiced assumption that there is something pathological with the sexuality and/or sexual preferences of lesbian women and that it needs to 'corrected' or 'cured' through rape (Padmanabhanunni, 2010). Lesbian women who display gender atypical behaviour (i.e., normative attributes ascribed to masculinity) in dress code, behaviour, and appearance are particularly vulnerable and punished through rape for their presumed subversive behaviour (Judge \& Nel, 2008; Nel, 2005). Survivors of corrective rape report experiencing verbal abuse prior to the rape focused on "teaching [them] a lesson" and 
"showing them how to be a real woman" (Mieses, 2009, p. 2). There are no official statistics on the prevalence of 'corrective rape,' as police records do not capture the sexual orientation of the victim or the motivations behind specific assaults. However, reports from non-governmental organisations (NGO's) indicate that reported incidents have been increasing (Anguita, 2011).

The psychological responses of individuals victimised on the basis of their sexual orientation resemble that of victims of other forms of trauma and include post-traumatic stress disorder (PTSD) and depression (Roberts, Austin, Corliss, Vandermorrs, \& Koenen 2010). However, existing literature (Szymanski \& Balsam, 2011) emphasises that, compared to their heterosexual counterparts, the victimisation of those with samesex sexualities needs to be conceptualised with an understanding that these experiences occur against the backdrop of pervasive prejudice and discrimination. Root (1992) terms this on-going cultural victimisation, 'insidious trauma.' One implication of insidious trauma is internalised heterosexism ( $\mathrm{IH}$ ), involving the acceptance of negative social stereotypes around those with same-sex sexualities, and this can lead to the individual believing that they are immoral and deserving of abuse (Gold, Dickstein, Marx, \& Lexington, 2009). These appraisals can enhance distress associated with trauma and inhibit disclosure of victimisation (Alessi et al., 2013). Even if the victim discloses the trauma, the heteronormative cultural environment (i.e., where heterosexuality is seen as the only normal and acceptable sexual orientation) means that responses of practitioners and other service providers may not meet the needs of those with same-sex sexualities, thereby enhancing distress and social isolation (Balsam, 2002, 2003).

Szymanski (2005) presents one of the few studies to identify distinct aspects that require clinical attention in work with sexual minority clients who have been victimised on the basis of their sexual orientation. Szymanski (2005) emphasises that, because acts of victimisation occur in the context of insidious trauma, the clinician needs to assess the client's history of experiences of heterosexism to understand how it has shaped the client's life and influenced her current problems. Where the client has experienced childhood sexual abuse (CSA), it is important to recognise that such abuse precipitates early awareness of sexuality, which can lead to the client then 'coming out' to family members so as to assuage feelings of confusion and distress (Marshall et al., 2008). Children or youth who disclose same-sex attractions have been found to be vulnerable to verbal and physical abuse and ostracism within their families, resulting in feelings of alienation, confusion, and shame (Rosario, Schrimshaw, \& Hunter, 2009; Ryan, Huebner, Diaz, \& Sanchez, 2009). Rejection by family members can precipitate behaviours that enhance risk of revictimisation, including running away from home or abusing substances (Balsam 2002, 2003). Understanding the client's history of exposure to insidious trauma can facilitate the generation of a comprehensive case formulation and appropriate treatment plan.

Szymanski (2005) also argues that a significant consequence of pervasive experiences of prejudice and discrimination is $\mathrm{IH}$ and that clinicians need to attend to the ways in which clients have internalised negative stereotypes and assumptions about same-sex sexualities (Balsam, 2003). IH can have an impact on the client's appraisals of the trauma, leading to self-blame and self-punitive behaviours (Gold et al., 2009). It also 
can influence expectations of the reactions of others to disclosure of victimisation, enhancing distress and social isolation. For this reason, identifying and challenging these beliefs is critical in helping clients understand how living in a heteronormative context influences their feelings and appraisals around their sexuality (Kashubeck-West, Szymanski, \& Meyer, 2007).

A third component of treatment, emphasised by Szymanski (2005), involves enhancing social support. Although this constitutes a central component of almost all treatment protocols for traumatised clients (Padmanabhanunni \& Edwards, 2012), Szymanksi (2005) and other researchers (Morris \& Balsam 2003) have emphasised that, in work with sexual minority clients, such support must involve stronger connections to lesbian, gay, bisexual and, transgender (LGBT) networks and feminist organisations. This is said to empower clients, normalise their sexuality and encourage them to work with others in addressing heterosexism.

Szymanski's (2005) guidelines are highly relevant but largely aimed at counsellors working within the context of tertiary education institutions and who serve campus communities. Therefore, the transportability of these clinical recommendations to real world settings remains uncertain. In South Africa, few studies could be located focusing on clinical practice with sexual minority clients exposed to trauma. Work by Peeke, Moletsane, Tshivhula and Keel (1998) presents an exception and provides a short vignette on psychotherapy with a lesbian woman victimised through the practice of 'jackrolling,' where she was repeatedly raped by a stream of men. The client received antagonistic responses from a police officer and subsequently decided against placing a charge against her attackers. Peeke et al. (1998) reported that such heterosexist reactions enhanced the client's mistrust, and this represented a significant obstacle to the formation of a therapeutic alliance.

This paper documents the assessment and treatment of Sanele, a lesbian-identified South African survivor of CSA who, as an adult, was raped and later gang raped. It is a detailed case study that lends insights into the role of heterosexism in shaping vulnerability to victimisation and the process of recovery. It provides practical recommendations for clinicians working with sexual minority clients and highlights distinct features that require clinical attention.

\section{Case Context and Research Method}

Sanele (23) was referred for treatment by a university student involved in advocacy around LGBT rights after she disclosed having been raped 7 months previously. As will become evident, treatment was unsuccessful. Despite this, the case narrative offers an opportunity for identifying distinct challenges to the treatment of sexual minority clients in South Africa and highlights the implications for clients when there is an absence of safety and support in their external environment.

The current study formed part of a research project in which systematic case studies were used to examine the transportability of Ehlers and Clark's (2000) cognitive therapy (CT) for PTSD to South African conditions. CT represents one of the most efficacious treatment protocols for PTSD (Clark \& Ehlers 2005; Ehlers \& Clark, 2000; Ehlers, 
Clark, Hackmann, McManus, \& Fennell, 2005; Grey, Young, \& Holmes, 2002) but lack of familiarity with the model, among local clinicians, and concerns around its crosscultural applicability inhibit its use (Padmanabhanunni, 2010). The project aimed to remedy this situation by generating a series of systematic case studies, several of which have been published or are available as online dissertations (Boulind \& Edwards, 2008; Davidow \& Edwards, 2007; Karpelowsky \& Edwards, 2005; Laas, 2009; Smith, 2006; Swartz, 2007; Van der Linde \& Edwards, 2013). For her doctoral thesis, the first author (Padmanabhanunni, 2010) wrote seven case studies on the treatment of PTSD following rape, including the study discussed here.

Systematic case studies represent a form of research that complements randomisedcontrolled trials (RCT's) as a means of developing evidence-based practice (Dattilio, Edwards, \& Fishman, 2010; Edwards, 2010, 2013; Fishman, 2005). Systematic case studies are able to provide nuanced insights into phenomena that are not typically accessible to approaches using group comparisons or surveys but that are of significant practical utility to clinicians (Padmanabhanunni, 2010). This includes information around specific obstacles to treatment engagement, the rationale behind choice of interventions, events during and between sessions, and interventions experienced as valuable by the client. Systematic case studies are practitioner oriented in that they take into account the personal and contextual features of the client's life and the intricacies of clinical practice including building a therapeutic alliance, assessment, case formulation, and treatment planning (Edwards, 2013).

Sanele was assessed and treated by the first author (AP), under the supervision of the second author (DE) who was familiar with Ehlers and Clark's (2000) CT. CT is a flexible, formulation driven model that focuses on tailoring treatment to suit the individual needs of the client. It has two phases: the assessment phase and treatment phase. The assessment phase focuses on uncovering the nature of the trauma memory, identifying the main cognitive themes (i.e., problematic appraisals of the traumatic event and/or its sequelae), and detecting problematic cognitive/behavioural strategies that need to be targeted. It also includes provision of psycho-education around PTSD and a rationale for treatment. The treatment phase involves: modifying negative trauma-related appraisals; reducing intrusive re-experiencing through elaboration and contextualisation of the trauma memory and; dropping safety behaviours/problematic cognitive strategies. As with other evidence-based treatments, there are three phases in using the approach (Edwards, 2009). The first focuses on safety and stabilisation, the second on assessing client motivation and understanding of the treatment model, and the third on active treatment and building social support.

Following Rhodes University's ethical procedures, Sanele signed informed consent forms for treatment and for information obtained to be used in reports and publications (in which pseudonyms were used). Assessment interviews were based on a standard clinical assessment, tailored to the requirements of the CT model, and the case was conceptualised and treated in terms of this model. Sanele could only come for session after work (5pm). To allow her to return home (which was $30 \mathrm{~km}$ away) before nightfall, assessment sessions were frequently short (30min), while treatment sessions were 40 minutes. Sanele had 10 assessment sessions twice weekly (A1-A8) and 8 treatment sessions once a week (T1-T8) before prematurely terminating. She was 
moderately fluent in English, and AP proposed a translator, but Sanele adamantly refused, reporting she did not trust other people. Since AP understood isiXhosa reasonably well, Sanele was encouraged to speak in isiXhosa whenever she struggled to convey her experiences in English, and she did so infrequently. When she did speak isiXhosa, AP was able to understand her. The data sources on which this study was based are:

1. Audio recordings: verbatim transcripts were created from recordings. For quality control, the transcript of one session was randomly selected and assessed by an independent assessor using an evaluation form. No distortions were found in the transcript.

2. Session records: detailed summaries of events in session, including the clinician's experience of session and observations of the client.

3. Supervisory notes: on issues discussed and suggestions made during weekly case supervision.

Based on these sources, the following data reductions were generated, according to the guidelines provided by Fishman (2005) for the online journal Pragmatic Case Studies in Psychotherapy:

4. Assessment summary, including a comprehensive case history and account of presenting problems and diagnoses.

5. Case formulation, organised into predisposing, precipitating, and maintaining factors understood to be contributing to the client's presenting problems, and treatment plan.

6. Therapy narrative created through synoptic thematic analysis that entailed identifying, analysing, and reporting on themes or patterns that occurred in the data set and were relevant to the research questions.

7. These summaries have been abbreviated for this presentation and written as first person accounts by the therapist-researcher (AP).

\section{Assessment Summary \\ Sanele's History}

Sanele and her brother (Thabo) were raised in a disadvantaged township settlement by their mother (Siboniso) who severely abused alcohol. When Sanele was 3 years old, her mother insisted that she accompany her to the shebeen (i.e., a tavern where alcohol is sold) while her 8-year-old brother remained home alone. Her earliest memories involved fearing for her mother's safety and guiding her home each night. Sometime during this period, Siboniso became involved with a man who was physically abusive towards Thabo. These attacks frightened Sanele, particularly because her mother did not intervene to stop the abuse.

Aged 7, Sanele started living with her grandmother (Thembi) as Siboniso could not support her financially. Between the ages of 7 and 12, she was repeatedly raped by her mother's boyfriend, who visited the home when Thembi was at work. Sanele told no one, fearing that such news would threaten Thembi's already fragile health and that her mother would reject her in favour of her boyfriend. Aged 8, she became aware of samesex attractions and disclosed this to her mother who reacted punitively, telling Sanele that only men were supposed to be attracted to women and her feelings were unnatural. She punished Sanele by severely scolding her and withholding materials she needed for school. Thembi died unexpectedly when Sanele was 12, leaving her shocked and deeply saddened. Fearing the rapist, she refused to return to her mother and relocated to live 
with her brother who worked on a farm. She dropped out of school and worked as a farm hand to support herself. Thabo abused alcohol and to cope with the loss of her grandmother and avoid distressing memories of the CSA, Sanele began to abuse alcohol. Aged 19, she relocated again to live with her maternal grandfather, but, after she disclosed that she was a lesbian woman, he forced her out of the home and refused to have any contact with her. This left her feeling alienated from her family. She found a job as a car guard, earned R500 a month and rented a small, dilapidated, single room in a township settlement and lived on her own.

Age 22, Sanele was raped by a stranger after visiting a shebeen. He requested that she accompany him to a nearby house on an errand and to use the toilet, but then physically assaulted her and threatened her with a knife before raping her. She went to a hospital where she was admonished by a male doctor who explicitly attributed the rape to her alcohol use, aggravating self-blame and distress. After opening a case docket at the police station, she was encouraged by the police to speak with a counsellor at a local NGO that provided counselling services. However, the counsellor explicitly attributed the rape to Sanele's sexual orientation, which distressed her even further.

Sanele subsequently experienced persistent inter-menstrual bleeding but refused medical care, fearing further negative reactions. She was reluctant to visit local clinics, because the nurses had often ridiculed her for gender atypical behaviour. Believing that the rape had occurred because of her sexual orientation, Sanele isolated herself in her room and punished herself by not eating food. Subsequently, food reminded her of the rape, leading to her avoiding eating and substantial weight loss. She felt constantly afraid while in her community as attacks against lesbian women were common, and some of her friends pretended to be heterosexual to avoid being hurt. Sanele was reluctant to contact her family for support, believing they would attribute the rape to her lesbian identity and blame her. The perpetrator was arrested shortly after she reported the rape but was then released on bail. Within three weeks, he was rearrested for having raped and murdered women while on bail.

\section{Presenting Problems and Diagnoses}

Sanele met criteria for PTSD (American Psychiatric Association, 2000). Intrusions of the rape took the form of nightmares and flashbacks of the rapist's face and the site of the trauma, triggered when she saw people who resembled the rapist, when she menstruated (she had been menstruating at the time of her rape) and when she approached a toilet. Sanele had symptoms of hyper-arousal and felt overly alert and easily startled. She actively avoided situations that reminded her of the rape, thinking and speaking about the rape, and used alcohol to avoid trauma memories and numb her distress.

She did not experience intrusions related to her CSA but actively avoided the perpetrator by not visiting her mother and by suppressing memories of the abuse. She met criteria for Major Depressive Disorder (moderate, recurrent) and felt guilty and ashamed, believing she was responsible for the rape and sad believing she could not turn to her family for support. She experienced suicidal ideation and often thought of killing herself. She had less of an appetite and had lost 6 kilograms since the trauma. Sanele met criteria for Borderline Personality Disorder (BPD) characterised by: an intense fear of abandonment; 
use of maladaptive strategies to regulate her distress and; impulsive behaviour. She met criteria for Substance Dependence (with physiological dependence): she consumed 5 litres of alcohol (mostly beer) on an almost daily basis; spent most of her income on alcohol; consumed alcohol at work, which interfered with her functioning and; found it difficult to limit her alcohol use.

\section{Case Formulation and Treatment Plan}

Experiences of childhood neglect and CSA compromised Sanele's capacity for affect regulation and interpersonal relatedness and facilitated the development of early maladaptive schemas (Young, Weishaar, \& Klosko, 2003), characterised by the assumption that she was deficient and that other people were untrustworthy. It is probable that CSA contributed to Sanele's early awareness of sexuality (Robohm, Litzenberger, \& Pearlman, 2003), resulting in her tentatively coming out to her mother, who responded punitively. Such punitive and rejecting responses can lead to IH. Gold et al. (2009) view IH as a pathological schema that leads to people with same-sex sexualities believing that they are defective, immoral, and deserving of abuse. Having witnessed her mother and brother use alcohol, Sanele resorted to alcohol to numb distressing emotions related to memories of CSA.

Alcohol abuse and PTSD had implications for her capacity to recognise potentially dangerous situations (Briere \& Lanktree, 2008), and living in an unsafe neighbourhood enhanced her vulnerability to revictimisation. To treat Sanele's PTSD, it was first necessary to ensure safety in her external environment and address her alcohol abuse. However, her socio-economic status meant that she could not afford accommodation in another area, and there was no women's shelter in the treatment setting. Sanele was actively encouraged to enrol in an inpatient substance abuse programme at a local psychiatric hospital but adamantly refused, stating that she did not trust other people and worried they would attribute her victimisation to her sexual orientation and be unsupportive. Her response informed intervention and the treatment plan involved developing a therapeutic alliance to rebuild her capacity for interpersonal trust and affect regulation. To enhance her safety outside of session, she was actively encouraged to only visit and leave the shebeen in the company of her female friends and preferably not visit the area at night. She agreed to this.

\section{Treatment Narrative}

\section{Sessions A1-A5: Preliminary Information and Building Trust.}

I first offered Sanele psycho-education about the nature and aims of therapy, which facilitated her recognition of therapeutic boundaries, including the length of sessions, confidentiality, and only contacting the therapist after hours if it was an emergency. Her inter-menstrual bleeding represented a serious physical health concern, and she was encouraged to seek private medical care (A3). The research grant paid for medical costs of treatment as these services were part of the larger funded project. I accompanied her for the consultation and, during the physical exam by a male physician, she experienced an intrusive memory of the rape and was extremely distressed. I subsequently offered psycho-education about triggering and guided her with 'then versus now' differentiation (Ehlers \& Clark 2000). She then was able to identify the differences between the doctor and the perpetrator, including that the perpetrator was obese while the doctor was fit,

\section{https://repository.uwc.ac.za/}


and his intentions were not to hurt her but to help her. This led to a moderate decrease in her intrusions and anxiety.

At A4 Sanele reported marked distress at the prospect of my going on leave for one week. I reassured her that I would return, but she remained unconvinced and requested that I write a motivational letter to "keep [her] going" while I was away. In the letter, I acknowledge her pain and reassured her that I cared for her and, once I returned, we would continue to work together. The day prior to my departure, Sanele unexpectedly visited my office and, upset to find no one present, angrily telephoned demanding to know where I was. I gently reminded her that we did not have an appointment but that I would see her in a week's time, but Sanele abruptly ended the call. She subsequently sent five text messages reminding me of my promise to return.

While I was away, Sanele sent two text messages telling me she was in tears and did not know how to cope but that I "should not call" or "worry about [her]". It was clear she was distressed and, when I contacted her, I learnt that she had unexpectedly been summoned to testify in the trial of the perpetrator and was very afraid at having to be in the same room as him. I reassured her that she would be protected in the court house and explained the procedure involved in testifying and advised her to ask a friend to accompany her. I encouraged her to contact me immediately after her court appearance. Sanele fainted after seeing the perpetrator in the court house and was taken to hospital. She contacted me and was extremely self-critical, believing she was "stupid" and "useless." I normalised her reaction and reassured her. The perpetrator was convicted based on the testimony of other women.

\section{Sessions A6-A10: Obtaining a fuller understanding of her distress.}

Sanele was relieved that I had fulfilled my promise by returning and continuing to work with her. With increased trust, she was more willing to share her life history, and I asked about her experiences as a lesbian woman. At age 16 she became involved in her first romantic relationship with a woman, which ended when her partner relocated. She later learnt that her partner had died and was shocked and deeply saddened. Sanele also tentatively disclosed that, five months previously, her current partner had unexpectedly passed away due to a heart condition. I empathised with her and encouraged her to engage with these experiences, but she would not, stating that she was determined to forget her losses.

Sanele was experiencing nightmares of the rape on an almost daily basis, and I offered her psycho-education around PTSD, which prompted her to provide a detailed verbal account of her rape. Retelling triggered feelings of sadness related to being alienated from family. Sanele also disclosed that she blamed herself for the rape and, believing that it was her sexuality that provoked the attacked, punished herself for being a lesbian woman. Her remarks in this respect can be seen in the segment below taken from the transcript of A8:

S: You see, after the rape, I locked myself in my room...and I didn't eat...for two weeks, I didn't even see anyone...Ijust locked myself in... I was punishing myself by not eating AP: You were trying to punish yourself? 
S: I thought...what am I going to say to my family, how do I explain this to them.....and then...if I spoke to them...they don't like that I'm a lesbian ... and if they hear that I was raped, they would say yes, the rape happened because you're a lesbian

AP: You felt that they would blame you and say it's because you're a lesbian that you were raped?

S: Ja... and I blame myself...for being a lesbian...I blame myselffor not having a family

Sanele also spoke of the sense of despondency she experienced as a lesbian woman: "Our lives... we're murdered, we're raped and we're not liked by our families..... I don't know what will become of us". I affirmed her concerns and empathised with her, explaining that people with same-sex sexualities experienced considerable challenges in being accepted and treated with respect by their families and communities.

\section{Sessions T1-T3: Enhancing trust.}

Sanele disclosed that she was now cutting herself with pieces of glass while at work to cope with triggering of the trauma memory, the physical pain served to distract her from emotional distress. Concerned about these harmful coping strategies, I offered her psychoeducation about triggering and suggested a translator, a clinical psychologist fluent in isiXhosa, be brought in to assist with retelling/reliving sessions. Sanele then threatened to terminate, believing that my intention was to abandon her. Feeling helpless and suicidal, she disclosed having bought battery acid with the intention of killing herself. Her reaction provided useful information to inform intervention - the therapeutic relationship was not secure enough, and active treatment for PTSD needed to be postponed to a later stage. I reassured Sanele that it was not my intention to refer her and focused on re-establishing trust by validating her needs and encouraging her to take the lead in session.

I helped Sanele cope with intrusions by normalising her reactions and encouraging her to engage in relaxing activities when distressed. Feeling reassured, she tentatively resumed sharing her life history. She disclosed her experiences of neglect with her mother and profound sadness at the loss of her girlfriend. However, she would not fully engage with her grief and, if prompted further, would dismiss the topic and report she was fine. Sanele established a tentative friendship with an elderly woman and started spending time in her company. I advised her to spend nights with this friend rather than on her own and she agreed to this and found that her nightmares occurred less frequently.

Sessions T4-T8: Clinician's absence, revictimisation and aftermath. Sanele was in therapy for 2 months before I went on leave for 4 weeks. I prepared her for this by consistently reminding her of the leave period and, feeling more secure, she reported that she was not distressed, because she knew I would return. I contracted with Sanele that, while I was away, I would contact her once a week at a specified time to touch base. I did so each week and Sanele responded by briefly reporting on her well-being. A week prior to my return, Sanele was abducted by four men while returning home. They physically assaulted her, hitting her on the head and rendering her unconscious, before perpetrating a gang rape. She regained consciousness hours later and found that she was naked and in an unfamiliar neighbourhood. She managed to walk to the home of a friend who called an ambulance and accompanied her to the hospital. Sanele suffered severe injuries to her 
face and remained in hospital for one week. Fearing the attending doctor's reactions and blaming herself for the assault, she kept the gang rape secret. After her release from hospital, she contacted me by telephone. I felt shocked at what she had endured and urged her to seek immediate psychological support at the local psychiatric hospital, but Sanele refused. With active encouragement, she eventually agreed to speak with a nurse she had befriended.

I met with Sanele after my return and found that she was in shock. I focused on stabilising her and actively encouraged her to seek out a new residence in a safer area, but she struggled to find alternative accommodation. Sanele reported that she had contacted her mother and disclosed the gang rape, and Siboniso had advised her to live with her, but, because of her mother's boyfriend, Sanele did not feel she could relocate.

Sanele disclosed that she was now using cannabis to cope with trauma memories and punished herself for the rapes by not eating, believing that it was her sexuality that provoked the gang rape. I emphasised her innocence and offered her empathy and support. The inter-menstrual bleeding returned, but Sanele repeatedly refused to seek medical attention, expecting negative reactions. She contacted me by telephone after T8, reporting that she was discontinuing psychotherapy and subsequently would not respond to any of my attempts to contact her.

\section{Discussion}

The narrative of Sanele's treatment process highlights the vulnerability of sexual minority clients. Sanele was exposed to repeated episodes of CSA during childhood and, as an adult, was raped and sought psychotherapy to cope with this trauma. While in therapy, she was exposed to a gang rape and shortly thereafter terminated treatment. Sanele's experiences of sexual victimisation in adulthood closely resemble incidents of 'corrective rape' perpetrated against other lesbian women in the same community (Trollope, 2012), making it highly probable that the rape and gang rape were motivated by prejudice and aimed at 'correcting' her sexuality. In addition to these traumas, Sanele's life history included repeated experiences of shame, rejection, and alienation based on her sexual orientation. In childhood, she became aware of same-sex attractions and disclosed this to her mother who responded punitively, which left her feeling rejected and alone and questioning whether her feelings were normal. Later in life, she disclosed to her grandfather, who immediately evicted her from the family home and wanted no further contact with her, leading to her alienation from the family. As an adult, whenever Sanele was ill and sought treatment at local clinics, she was mocked by the nurses for gender atypical behaviour. When she first sought professional help in coping with the ASA, she was told by a counsellor at a national NGO that, being a lesbian woman, she was to blame for the assault. Sanele also lived with a sense of constant threat owing to her knowledge that her sexuality was considered deviant and unacceptable in her community and that lesbian women were specifically targeted for victimisation.

Szymanski (2005) offered recommendations for clinical practice with sexual minority clients and identified the following as relevant for assessment and treatment: 
comprehensively assessing the client's history of insidious trauma; addressing IH and related self-blame; promoting the client's awareness of the relationship between the heteronormative context and the experience of self so as to challenge problematic assumptions around their sexuality and; enhancing social support, especially the client's connections to LGBT networks and feminist communities.

Szymanski's (2005) recommendations are highly relevant but are based on two assumptions: that there is a degree of safety in the client's external environment and; that the client has the internal resources and capacities to engage with treatment.

For women like Sanele, who live in adverse social circumstances characterised by poverty, community violence, heterosexism and the presence of those involved in their victimisation, there is a constant and very real sense of threat (Mieses, 2009). Lesbian women in South Africa are particularly vulnerable to victimisation, as they are perceived as undermining patriarchal gender norms, roles, and stereotypes (Judge \& Nel, 2008). The degree of violence in these acts of victimisation tends to be more pronounced compared to attacks against heterosexual women (Meises, 2009). This is evident in, for example, the brutal attack against Eudy Simelane, an openly lesbian woman who played soccer for the national women's team. She was gang raped, severely beaten and stabbed 25 times (Kelly, 2009). In the absence of physical safety in the external environment, it is difficult for clients to engage with individual outpatient treatment (Padmanabhanunni \& Edwards, 2012).

Experiences of repeated victimisation can compromise the capacity for self-protection (Ford \& Courtois, 2009). In Sanele's case, childhood neglect, repeated exposure to sexual abuse, and chronic experiences of victimisation based on her sexual orientation conferred vulnerability to negative internal working models of self and others, including IH (Gold et al. 2009). She believed that she was not worthy of care and protection and that other people could not be trusted. These beliefs affected her capacity to form meaningful relationships and adaptive social networks that could act as sources of protection (Rafaeli, Bernstein, \& Young, 2011). In addition, IH contributed to Sanele attributing the ASA to her having a deviant sexual orientation. This precipitated intense shame and selfpunitive behaviour. It is hypothesized that this lay behind her terminating therapy. Addressing Sanele's IH and related self-blame in the context of therapy was challenging as she would ultimately return to a heteronormative context that validated and maintained her appraisals of responsibility. For this reason, Szymansky (2008) and other researchers (Balsam 2003; Kashubeck-West et al., 2008) have suggested that clinicians address self-blame by encouraging stronger connections to LGBT networks and feminist communities so as to promote solidarity and normalise distressing reactions. However, in South Africa, these communities and networks are often only available in major cities. In the treatment setting, the only available LGBT network catered to university students and was not suited to meet the needs of mainstream clients from lower socio-economic backgrounds. As such, while in treatment, Sanele remained largely socially isolated. 


\section{What Supports and Services Would Have Been Necessary to Help Sanele?}

As evident from the treatment narrative, individual outpatient treatment was not ideal. The heterosexist context, the presence of those involved in her victimisation and her limited capacity for self-protection meant that she was at risk for continued revictimisation.

For Sanele to engage with and benefit from treatment, a closed residential treatment programme would have been a more appropriate starting point. These programmes involve intensive, multi-disciplinary treatment and offer a safe, structured and predictable environment (Briere \& Lanktree, 2008; Chiesa, Drahorad, \& Longo, 2000; Coulter, 2011; Rivard et al., 2004). As such, clients are protected from the risk of revictimisation and self-harming behaviour. In South Africa, however, there is an absence of such facilities for traumatised populations at the state level, with the majority of these programmes dedicated to alcohol and drug abuse (Padmanabhanunni \& Edwards, 2012). Existing programmes developed in other countries have reported promising results. Busuttil (2005), for example, describes the development and implementation of a 90-day residential programme for clients exposed to repeated trauma and suffering from complex PTSD. The programme was divided into three thirty-day phases, based on established treatment protocols and focusing on: safety and stabilisation, active treatment engagement, and preparing for termination. Patients showed marked decline in symptoms of PTSD and self-harming behaviour by the end of treatment.

A similar 90-day programme would have been more appropriate for Sanele. Concomitant to individual psychotherapy, group and family therapy could be included in the treatment protocol so as to foster interpersonal skills and rebuild social support. Group therapy involving other lesbian-identified women, for example, would have helped generate universality (Yalom \& Leszcz, 2005), thereby addressing IH and feelings of alienation (Farrell, Shaw, \& Webber, 2009). In addition, family therapy sessions aimed at addressing problematic assumptions around same-sex sexualities could create greater acceptance. Inviting Sanele's grandfather and other relevant family members for a session, for example, may have been useful in creating a support base for her. In the absence of safety and support in the larger environment, lesbian women like Sanele are merely at risk of further victimisation. They do not possess the internal resources or capacities for self-protection and, owing to a heteronormative cultural context, are easy targets for potential perpetrators. For these women to be able to engage in psychotherapy and develop the skills necessary for self-protection, issues related to safety and security in the external environment first need to be addressed.

\section{Conclusion}

This paper documented the assessment and treatment process with Sanele, a lesbianidentified survivor of multiple traumatic events. The paper affirms the findings of existing studies that direct victimisation of people with same-sex sexualities occurs against a backdrop of insidious trauma, and this has distinct psychological implications. In addition, the paper underscored the importance of safety and support in the client's external environment and the devastating consequences when such security is absent. 


\section{References}

Alessi, E. J., Meyer, I. H., \& Martin, J. I. (2013). PTSD and sexual orientation: An examination of criterion A1 and non-criterion A1 events. Psychological Trauma: Theory, Research, Practice and Policy, 5(25), 149-157.

American Psychiatric Association. (2000). DSM-IV-TR: Diagnostic and statistical manual of mental disorders (4th ed., text rev.). Washington, DC: Author.

Anguita, L. A. (2011). Tackling corrective rape in South Africa: The engagement between the LGBT CSO's and the NHRI's (CGE and SARCHI) and its role. The International Journal of Human Rights, 16(3), 489-516.

Balsam, F. K. (2002). Traumatic victimization in the lives of lesbian and bisexual women. Journal of Lesbian Studies, 7(1), 1-14.

Balsam, F. K. (2003). Trauma, stress and resilience among sexual minority women: Rising like a phoenix. Journal of Lesbian Studies, 7(4), 1-8.

Briere, J., \& Lanktree, C. (2008). Integrative treatment of complex trauma for adolescents (ITCT-A): A guide for the treatment of multiply-traumatized youth. Retrieved from http://www.johnbriere.com/Adol\%20Trauma\%20Tx\%20Manual \%20\%20Final\%208_25_o8.pdf

Boulind, M., \& Edwards, D. J. A. (2008). The assessment and treatment of post-abortion syndrome: A systematic case study from Southern Africa. Journal of Psychology in Africa, 18, 539-548.

Busuttil, W. (2005). The development of a 90-day residential program for the treatment of complex posttraumatic stress disorder. Journal of Aggression, Maltreatment and Trauma, 12(1), 29-55.

Chiesa, M., Drahorad, C., \& Longo, S. (2000). Early termination of treatment in personality disorder treatment in a psychotherapy hospital: Quantitative and qualitative study. British Journal of Psychiatry, 177, 107-111.

Clark, D. M., \& Ehlers, A. (2005). Posttraumatic stress disorder: From cognitive theory to therapy. In R. L. Leahy (Ed.), Contemporary cognitive therapy (pp. 141-160). New York, NY: Guilford Press.

Coulter, S. (2011). Systemic psychotherapy as an intervention for post-traumatic stress responses: An introduction, theoretical rationale and overview of developments in an emerging field of interest. Journal of Family Therapy, 141-160. Retrieved from http://onlinelibrary.wiley.com/doi/10.1111/j.1467-6427.2011.0 0570.x/pdf

Dattilio, F. M., Edwards, D. J. A., \& Fishman, D. B. (2010). Case studies within a mixed methods paradigm: Towards a resolution of the alienation between researcher and practitioner in psychotherapy research. Psychotherapy: Theory, Research, Practice \& Training, 47, 427-441.

Davidow, A. S., \& Edwards, D. J. A. (2007, July). Treatment of PTSD and depression in a black South African rape survivor: A case based evaluation of the Ehlers and Clark's clinical model. Paper presented at the World Congress of Behavioral and Cognitive Therapies in Barcelona International Convention Centre, Barcelona, Spain.

Edwards, D. J. A. (2009). Treating posttraumatic stress disorder in South Africa: An integrative model grounded in case-based research. Journal of Psychology in Africa, 19(2), 189-199. 
Edwards, D. J. A. (2010). Using systematic case studies to investigate therapist responsiveness: Examples from a case series of PTSD treatments. Pragmatic Case Studies in Psychotherapy, 6(4), 255-275.

Edwards, D. J. A. (2013). Responsive integrative treatment of clients with PTSD and trauma-related disorders: An expanded evidence-based model. Journal of Psychology in Africa, 23(1), 7-20.

Ehlers, A., \& Clark, D. M. (2000). A cognitive model of posttraumatic stress disorder. Behaviour Research and Therapy, 38, 319-345.

Ehlers, A., Clark, D. M., Hackmann, A., McManus, F., Fennell, M., Herbert, C., \& Mayou, R. A. (2003). A randomized controlled trial of cognitive therapy, self-help booklet, and repeated assessment as early interventions for PTSD. Archives of General Psychiatry, 6o, 1024-1032.

Ehlers, A., Clark, D. M., Hackmann, A., McManus, F., \& Fennell, M. (2005). Cognitive therapy for post-traumatic stress disorder. Behaviour Research and Therapy, 43, 413-431.

Farrell, J. M, Shaw, I. A., \& Webber, M. A. (2009). A schema-focused approach to group psychotherapy for outpatients with borderline personality disorder: A randomized controlled trial. Journal of Behavior Therapy and Experimental Psychiatry, 40, 317-328.

Fishman, D. B. (2005). From single case to database: A new method for enhancing psychotherapy practice. Pragmatic Case Studies in Psychotherapy, 1(1), 1-50.

Ford, J. D., \& Courtois, C. A. (2009). Defining and understanding complex trauma and complex traumatic stress disorders. In C. A. Courtois \& J. D. Ford (Eds.), Treating complex traumatic stress disorders: An evidence-based guide (pp. 13-31). New York, NY: Guilford Press.

Gold, S. D., Dickstein, B. D., Marx, B. P., \& Lexington, J. M. (2009). Psychological outcomes among lesbian sexual assault survivors: An examination of the roles of internalised homophobia and experiential avoidance. Psychology of Women Quarterly, 33, 54-66.

Grey, N., Young., K., \& Holmes, E. (2002). Cognitive restructuring within reliving: A treatment for peritraumatic emotional "hotspots" in posttraumatic stress disorder. Behavioural and Cognitive Psychotherapy, 30, 37-56.

Judge, M., \& Nel, J. A. (2008). Exploring homophobic victimisation in Guateng, South Africa: Issues, impacts and responses. Acta Criminologica, 21(3), 19-36.

Karpelowsky, B. J., \& Edwards, D. J. A. (2005). Trauma, imagery and the therapeutic relationship: Langu's story. Journal of Psychology in Africa, 15, 185-195.

Kashubeck-West, S., Szymanski, D., \& Meyer, J. (2008). Internalised heterosexism: Clinical implications and training considerations. The Counselling Psychologist, 36(4), 615-630.

Kelly, A. (2009, March 12). Raped and killed for being a lesbian: South Africa ignores 'corrective' attacks. The Guardian Online. Retrieved from http://www.guardian.co.uk/world/2009/ mar/12/eudy-simelane-corrective-rapesouth-africa

Laas, S. J. (2009). An examination of the Ehlers and Clark cognitive therapy model within the South African context: The assessment and treatment of a survivor of violent criminal victimization (Unpublished research report). Rhodes University, Grahamstown, South Africa. 
Lovelle, C. (2008). Dialectical behavioral therapy and EMDR for adolescents in residential treatment: A practical and theoretical perspective. Residential Treatment for Children and Youth, 23(1), 27-43.

Marshall, M. P., Friedman, M. S., Stall, R., King, K. M., Miles, J., Gold, M. A., . . Morse. J. Q. (2008). Sexual orientation and adolescent substance abus e: A meta-analysis and methodological review. Addiction, 556.

Mieses, A. (2009). Gender inequality and corrective rape of women who have sex with women. Gay Men's Health Crisis Treatment Issues, December, 1-3.

Morris, J. F., \& Balsam, K. F. (2003) Lesbian and bisexual women's experiences of victimization: Mental health, revictimisation, and sexual identity development. Journal of Lesbian Studies, 7(4), 67-85.

Nel, J. (2005). Hate crimes: A new category of vulnerable victims for a new South Africa. In L. Davis \& R. Snyman (Eds.), Victimology in South Africa (pp. 240-254). Pretoria, South Africa: Van Schalk.

Padmanabhanunni, A. (2010). A series of systematic case studies on the treatment of raperelated PTSD in the South African context: Implications for practice and policy. Doctoral thesis, Rhodes University, Grahamstown, South Africa.

Padmanabhanunni, A., \& Edwards, D. (2012). Treating complex post-traumatic stress disorder following childhood neglect, sexual abuse and revictimisation: Interpretative reflections on the case of Khuselwa. Child Abuse Research in South Africa, 13(1), 40-54.

Payne, C., \& Edwards, D. J. A. (2009). What services and supports are needed to enable trauma survivors to rebuild their lives? Implications of a systematic case study of cognitive therapy with a township adolescent girl with PTSD following rape. Child Abuse Research in South Africa, 1O(1), 27-40.

Peeke, S., Moletsane, T., Tshivhula, C., \& Keel. U. (1998). Working with emotional trauma in a South African community: A group perspective. Psychoanalytical Psychotherapy in South Africa, 6, 12-28.

Rafaeli, E., Bernstein, D. P., \& Young, J. (2011). Schema therapy: The CBT distinctive features Series (New York, NY: Routledge).

Rivard, J. C., McCorkle, D., Duncan, M., Pasquale, L. E., Bloom, S. L., \& Abramovitz, R. (2004). Implementing a trauma recovery framework for youths in residential treatment. Child and Adolescent Social Work Journal, 21(5), 529-550.

Roberts, A.L., Austin, B. S., Corliss, L.H., Vandermorrs, K. A., \& Koenen, C. K. (2010). Pervasive trauma exposure among US sexual orientation minority adults and risk of post-traumatic stress disorder. American Journal of Public Health, 10o(12), 2433-2441.

Robohm, J. S., Litzenberger, B. W., \& Pearlman, L. A. (2003). Sexual abuse in lesbian and bisexual young women: Associations with emotional/behavioral difficulties, feelings about sexuality, and the "coming out" process. Journal of Lesbian Studies, 7(4), $31-47$.

Root, M. P. (1992). Reconstructing the impact of trauma on personality. In L. S. Brown \& M. Ballou (Eds.), Personality and psychology: Feminist reappraisals (pp. 229265). New York, NY: Guilford Press.

Rosario, M., Schrimshaw, E. W., \& Hunter, J. (2009). Disclosure of sexual orientation and subsequent substance abuse among lesbian, gay, and bisexual youths: Critical role of disclosure reactions. Psychology of Addictive Behaviours, 23(1), 175-184. 
Ryan, C., Huebner, D. Diaz, R. M., \& Sanchez, J. (2009). Family rejection as a predictor of negative health outcomes in white and Latino lesbian, gay, and bisexual young adults. Pediatrics, 123(1), 346-352.

Smith, T. A. (2006). Frozen in time to reclaiming one's life: The evaluation of the Ehlers and Clark Cognitive Therapy Model in the assessment and treatment of a hijacking survivor (Unpublished research report). Rhodes University, Grahamstown, South Africa.

Smith, I., Oades, L. G., \& McCarthy, G. (2012). Homophobia to heterosexism: Constructs in need of revisitation. Gay and Lesbian Issues and Psychology Review, 8 (1), 3444.

Swartz, K. (2007). Contextual obstacles to the delivery of effective psychological treatment of PTSD in a South African community setting (Unpublished research report). Rhodes University, Grahamstown, South Africa.

Swim, J. K., Pearson, N. B., \& Johnston, K. E. (2007). Daily encounters with heterosexism: A week in the life of lesbian, gay, and bisexual individuals. Journal of Homosexuality, 53(4), 31-48.

Szymanski, D. M. (2005). Heterosexism and sexism as correlates of psychological distress in lesbians. Journal of Counselling and Development, 43, 355-360.

Szymanski, D. M., \& Balsam. K. (2011). Insidious trauma: Examining the relationship between heterosexism and lesbians' PTSD symptoms. Traumatology, 17(2), 4-13.

Trollope, C. (2012, August 9). I'm not going to be ashamed. Grocott's Mail Online. Retrieved from http://www.grocotts. co.za/content/im-not-going-be-ashamed-o9o8-2012

Van der Linde, F., \& Edward, D. (2013). "It's like uprooting trees": Responsive treatment for a case of complex post-traumatic stress disorder following multiple rapes. Journal of Psychology in Africa, 23(1), 21-30.

Yalom, I., \& Leszcz, M. (2005). The theory and practice of group psychotherapy. New York, NY: Basic Book.

Young, J. E., Weishaar, M. E., \& Klokso, J. W. (2003). Schema therapy: A practitioner's guide. New York, NY: Guilford Press.

\section{Author Notes}

The authors express their appreciation to Sanele for sharing her story and allowing clinical material to be used for research purposes.

AP acknowledges the support of the Andrew Mellon Foundation and the National Research Foundation of South Africa in supporting her doctoral research.

DE acknowledges the financial support of the National Research Foundation of South Africa and the Rhodes University 